\title{
Visceral Surface of the Liver
}

National Cancer Institute

\section{Source}

National Cancer Institute. Visceral Surface of the Liver. NCI Thesaurus. Code C33883.

The serous membrane that covers the surface of the liver. 